\title{
A mudança no discurso educacional das ONGSIAIDS no Brasil: concepções e desdobramentos práticos (1985-1998)
}

GÓIS, J. B. H. The change in the NGOS/AIDS educational speech in Brazil: conceptions and practical results (1985 -1998), Interface - Comunic, Saúde, Educ, v.7, n.13, p.27-44, 2003.

This article examines the main statements and conceptions present in the educational speech produced by the Brazilian AIDS Non Governmental Organizations - ASOs and examines how these speechs influenced the production of intervention projects. The paper identifies two main interconnected phases in such speechs: the universalist and the convergent ones. Without denying the importance of the work of the ASOs, the article asserts that their use of the conception of reason sometimes led them to use simplistic and punitive forms of intervention.

KEY WORDS: Education; Health; AIDS; Non-Governmental Organizations.

Este artigo examina as principais concepções contidas nos discursos educacionais das Organizações NãoGovernamentais de Luta Contra a AIDS brasileiras (1985-1998) e analisa como tais discursos incidiram na elaboração de projetos de intervenção. O trabalho indica a existência de duas fases principais do discurso (universalista e focalista) e salienta o intercâmbio de características entre uma e outra. Sem negar a relevância do trabalho das ONGs/AIDS, conclui-se que a adesão acrítica à noção de razão levou essas organizações muitas vezes à elaboração de modelos analíticos e interventivos simplistas e punitivos.

PALAVRAS-CHAVE: Educação; Saúde; AIDS; Organizações Não-Governamentais.

${ }^{1}$ Professor Adjunto, Escola de Serviço Social da Universidade Federal Fluminense; Pesquisador do CNPq. <jbhg@uol.com.br> 
GÓIS, J. B. H.

\section{Introdução}

Em torno da epidemia de AIDS foram travados inúmeros debates acerca da sua origem, da identidade sócio-sexual e racial dos seus atingidos e das medidas a serem tomadas para sua superação. Tais debates, particularmente nos anos iniciais da década de 1980, conduziram à criação de uma série de representações que estabeleceram a divisão entre os já infectados em vítimas-culpadas e vítimas-inocentes, indicaram aqueles com maior probabilidade de virem a contrair o vírus e sinalizaram quem eram os responsáveis pela introdução e expansão da AIDS no solo brasileiro (Parker, 1994). Nesse contexto, grupos que já eram historicamente objeto de discriminação e preconceito - homossexuais, negros, prostitutas, dentre outros - tornaram-se alvos fáceis de culpabilidade. Para a difusão dessas representações em muito colaboraram as diferentes organizações da mídia. A partir delas foram construídas imagens preconceituosas sobre a doença $e$ o doente que modelaram muitas das respostas à epidemia e geraram uma sub-epidemia conexa: a do medo, da violência e do desespero (Neto, 1999). A este complexo contexto adicionava-se ainda o descaso governamental para com os perigos reais e potenciais da AIDS, o que levou ao atraso no lançamento de ações globais de vigilância sanitária, assistenciais $e$ educacionais que pudessem impedir sua expansão (Camargo Jr, 1999). Muito em conseqüência disso, a doença alastrou-se e agressivamente atingiu os setores mais marginalizados da população brasileira.

É dentro desse contexto de crescimento da epidemia, falta de ação governamental e expansão de discursos preconceituosos pela mídia, que foram construídas as nossas organizações não-governamentais de luta contra a AIDS - ONGs/AIDS (Altman, 1995; Góis, 1998; 1999; 2000a). Tais organizações opuseram-se às formas de intervenção discriminatórias $e$ segregacionistas e buscaram produzir uma linguagem descritiva da epidemia que não fosse fundada no preconceito e no desejo de criar novas divisões sociais. Para fazê-lo, entraram em confronto direto com segmentos conservadores detentores de grande poder. No que pode ser descrita como uma prolongada batalha político-cultural contra tais segmentos, essas organizações implementaram um conjunto de ações de enfrentamento à epidemia no qual, em par com retórica da solidariedade, a educação assumiu um papel fundamental. É o exame dos discursos e das ações educacionais defendidas por elas entre os anos de 1985 e 1998 que constitui a matéria examinada neste artigo ${ }^{2}$. Ao fazê-lo, tento contribuir para o re-exame de práticas educativas que, nos marcos atuais da expansão da epidemia de AIDS, perfazem uma das mais concretas esperanças de sobrevivência para uma enormidade de indivíduos em situação de maior vulnerabilidade ao HIV.

Dois tempos dos discursos e ações educacionais das ONGs/AIDS Apoiadas nas descobertas científicas que determinavam a natureza biológica da AIDS e demarcavam os mecanismos de infecção (Erni, 1994) (a troca de determinados fluídos corporais), as ONGs(AIDS recusaram-se a apoiar quaisquer propostas de controle da epidemia que não fossem formuladas exclusivamente a partir desses dados. Desta forma, elas combateram

\footnotetext{
2 Embora a análise aqui realizada faça mais referências às ONGs/AIDS e ao contexto do Rio de Janeiro, ela parece válida, no geral, para as experiências educacionais levadas a cabo em outros Estados. Isto porque as inúmeras divergências entre as ONGs/AIDS não impediram que ao longo dos anos se consolidasse um discurso educacional que não mais exibiria variações em torno dos seus princípios básicos e que, portanto, passou a apresentar-se como discurso oficial.
} 
${ }^{3}$ Esta análise, porque centrada na questão da transmissão do HIV através do contato sexual, não se refere diretamente à atuação das ONGs/ AIDS na esfera da transmissão vertical ou da AIDS transfusional, por exemplo. inúmeras alternativas vistas por alguns setores médicos, leigos e religiosos como positivas para o controle da epidemia - por exemplo, a redução de parceiros, a monogamia e, no limite, a abstinência - pelo que tais propostas continham de associação entre a infecção pelo HIV e condutas morais supostamente reprováveis. Ao assumir esta postura, tais organizações buscavam reafirmar que, mesmo em tempos de AIDS, as nossas vidas sóciosexuais poderiam permanecer como antes e que as medidas de luta contra a doença a serem desenvolvidas deveriam pautar-se pelo respeito a esta posição. Dentro deste quadro de percepções, a educação para a AIDS proposta pelas ONGs erigiu-se como uma medida de controle sanitário que contemplava em seu interior a defesa de um princípio político - o da liberdade das múltiplas expressões do desejo sexual. Em função disto elas concentraram suas expectativas de controle da epidemia e desenvolveram muito de suas práticas educativas em torno do então único elemento conhecido capaz de servir de barreira à troca de fluidos corporais potencialmente infectados entre um corpo e outro: a camisinha masculina. ${ }^{3}$ Para fins expositivos agrupo tais práticas e as idéias que lhes são subjacentes em duas fases, ambas discutidas nas próximas seções.

\section{A fase campanhista $e$ a ênfase na informação}

No Brasil, ações no sentido do estímulo ao uso da camisinha, mesmo que tímidas, foram levadas a cabo já em 1983. Grupos gays de São Paulo e da Bahia, por exemplo, incorporaram tal orientação às suas propostas educacionais e tentaram difundi-la. A confirmação, em 1984, de que a doença era causada por um vírus específico fortaleceu o pressuposto de que seu uso generalizado era a alternativa mais viável do ponto de vista sanitário e mais avançada do ponto de vista político. Em 1987, o presidente do Grupo Gay da Bahia, Luís Mott, declarava a vitória do condom sobre os preconceitos e a sua afirmação como personagem central do cenário sexual brasileiro dos anos oitenta do século XX. Servindo-se de um grande número de fontes jornalísticas, Mott assegurava que o condom superara o status de objeto obscuro e o apresentava como elemento capaz de nos livrar do mal do século. Muito do seu otimismo assentava-se no aumento radical do consumo após as primeiras campanhas de divulgação. Dizia ele:

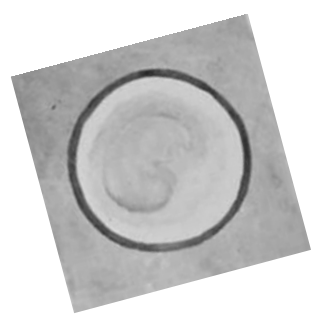

Pesquisas recentes comprovam que também aqui cresce dia-a-dia o uso dos preservativos. À pergunta 'você passou a usar preservativos em suas relações sexuais por causa da AIDS?', em dezembro de 85, 6\% responderam 'sim', elevando-se para $27 \%$ as respostas positivas em fevereiro de 87 - todos os jovens entre 15 e 25 anos. A mesma questão foi colocada para homens adultos, homossexuais e bissexuais: em dezembro de $85,17 \%$ responderam 'sim', elevando-se para $49 \%$ quatorze meses depois, comprovando-se que os chamados 'grupos de risco' têm manifestado maior cuidado profilático do que a população em geral. Pesquisas de opinião em farmácias e estabelecimentos comerciais comprovam que as mulheres brasileiras, como as norteamericanas, tornaram-se cada vez mais, também elas, compradoras e divulgadoras do uso da camisinha. (...) (Mott, 1987, p.36) 
GÓIs, J. B. H.

Uma vez atingido este estágio de conhecimento e certezas, as ONGs/AIDS concentraram muito dos seus esforços em ações que pudessem contribuir para a universalização do acesso ao preservativo de borracha e na implementação de campanhas informativas capazes de difundir sua importância.

Nesse contexto, elas construíram o diagnóstico de que a expansão da epidemia residia em grande medida nas características (superficialidade, principalmente) e volume (pequeno) da informação disponibilizada pelas agências governamentais. Elas também destacavam que o tipo de informação disponibilizada pelo Estado, além de reforçar percepções equivocadas, produzia mudanças negativas na experimentação social da doença, tornando-a mais dolorosa e letal. Outrossim, diziam que tal informação criava as condições necessárias para a expansão do curandeirismo, para a consolidação de uma ciência arrogante e para a difusão do medo o qual, a seu turno, produzia a clandestinização do doente. Sobre tal obscurantismo, propunham as ONGs/AIDS, o conhecimento crítico deveria lançar novas luzes. Assim, a informação era vista como um valor político, como uma alavanca de libertação $e$, principalmente, como fator democratizante. Informação assumia, antes de tudo, o papel de agente salvador: quanto mais rápido ela e o condom chegassem a uma pessoa, menor seria a probabilidade da sua infecção. Daí porque se dizia "que devem [deveriam] ser produzidas verdadeiras maratonas de informação, programas de horas, em horário nobre, onde se forneçam [fornecessem] os dados necessários para que cada um entenda $e$ decida" (ABIA, 1988, p.3).

A partir dessa pressuposição desenvolveu-se em ritmo e caráter campanhista a maior parte da educação anti-AIDS crítica em diversas cidades do país naquele período. As ONGs/AIDS foram às massas $e$ desencadearam um amplo processo de transmissão indiferenciada de informações para toda a população, visto por elas, uma vez superadas as tecnicalidades postas pela ciência e utilizadas uma linguagem popular, como uma tarefa de fácil execução.

Nesse contexto, a campanha para a divulgação do condom era expressão $e$, ao mesmo tempo, transmitia uma crença constituída de três componentes. O componente político informava que sexo era uma atividade saudável e prazerosa que não deveria ser abandonada. Do ponto de vista psicológico, anunciava-se que uma vez já conhecidos os mecanismos de transmissão, o pânico deveria ceder lugar a uma convivência menos tensa com a doença já que o seu evitar dependeria, e este é o componente sanitário, de se usar o condom a cada relação sexual, não importando onde ou com quem. Com isto, supunha-se, estaria assegurada a manutenção de princípios políticos libertários e a saúde (sexual) do povo.

Mas o que fazer diante dos inúmeros problemas apresentados pelos preservativos enquanto unidades materiais? Ou seja, como lidar com os recorrentes relatos de falhas de funcionamento associadas a defeitos de fabricação e ineficácia abaixo dos $100 \%$ supostos pela lógica do discurso educacional das ONGs/AIDS? Em outros termos, como lidar com as dúvidas

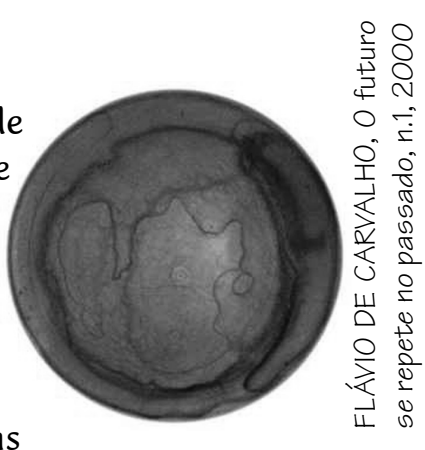
sobre a questão da eficácia do preservativo como forma de prevenção das 
doenças sexualmente transmissíveis em geral e do HIV em particular? A depender da amostra e dos procedimentos de análise, as pesquisas indicavam diferentes níveis de eficiência. Falhas decorriam tanto do uso inadequado, como das características inapropriadas para certas atividades sexuais. Esses números constituíam a indicação mais precisa de que, hetero-, homo- $e$ bissexuais não estavam totalmente protegidos do vírus com uso do condom. Em muitos casos, os estudos relataram, as falhas mecânicas conduziram ou à gravidez indesejada, ou à infecção ou a ambos. Tornando a situação ainda mais complexa, diversos alertas sugeriram que o problema não estava situado apenas nas deficiências do condom enquanto unidade material. Ao lado disso, vários estudos, desde o final dos anos oitenta e por toda a década de 1990, indicaram que a manutenção de um regime sexual no qual os preservativos de borracha fossem sempre um componente presente constituía uma pretensão infundada (Dean \& Meyer, 1995). No lastro otimista em que a campanha do condom defendida pelas ONGs/AIDS se dava, contudo, essas discussões assumiram uma importância secundária...ou nenhuma. A necessidade de manter a coerência entre a mensagem política $e$ a mensagem sanitária determinou que a reflexão sobre essas problemáticas fosse relegada a segundo plano. Sua importação para o terreno central do debate, em um momento de agressivos ataques de dados segmentos conservadores, poderia por em causa a confiança não somente no preservativo de borracha, como também na inteira pedagogia que começava a ser construída ${ }^{4}$. Assim, em vez de proceder a uma ampla avaliação dessas

${ }^{4}$ Neste artigo os termos educação e pedagogia anti-AIDS, embora possuam sentidos semelhantes, não são intercambiáveis. A educação anti-AIDS é entendida como o ensino da alteração/ eliminação de práticas que podem conduzir à infecção pelo HIV. Já a pedagogia anti-AIDS, incorporando as práticas educativas, assume uma dimensão maior no que toca aos conteúdos que quer ensinar e, com efeito, só pode ser

plenamente entendida quando vista nos leitos do processo civilizador na acepção que esse termo assume na obra de Elias (1994). questões, preferiu-se insistir que os problemas de adesão à nova ordem erótica estavam relacionados ao campo político- econômico: "Os problemas da camisinha são outros: em primeiro lugar é cara e nem sempre está disponível. Devemos lutar para que o governo controle qualidade e preço e a torne acessível para toda a população" (Abia, 1997a, s/p), asseverava a Associação Brasileira Interdisciplinar de AIDS - ABIA já no final dos anos de 1990.

Outrossim, persistiu-se na afirmação - apesar das indicações epidemiológicas em contrário - de que determinados grupos haviam incorporado definitivamente o condom ao seu cotidiano. Análises pouco fundamentadas de que as prostitutas, por exemplo, "aprenderam o uso correto do preservativo e não somente o usam para a sua segurança como para a segurança dos clientes" (Pim, 1994), conduziram a níveis de certeza confortadores. Daí porque a resposta da pedagogia ao fenômeno da inconsistência no uso do condom foi o aumento do esforço de sua erotização - uma perspectiva presente até hoje. Como ressalta uma brochura educativa do final dos anos 90, "A camisinha (...) pode introduzir uma nova brincadeira na transa e trazer mais consciencia para os parceiros sobre o sexo, porque os leva a falar sobre o assunto" (Abia, 1997a, s/p).

$O$ intuito era mostrar que, ao contrário das afirmações então correntes sobre a perda do prazer sexual causada pelo intruso de látex, o condom poderia ser, uma vez objeto de marketing positivo e explicadas as formas de utilizá-lo, facilmente inserido no menu de opções eróticas do povo brasileiro. Mais do que isso, sugeria-se que ele poderia tornar mais prazerosas aquelas já em uso. Esta é, sem dúvida, uma perspectiva que avançou pelos anos 90, 
constituindo uma peça central dos instrumentos e técnicas da pedagogia crítica anti-AIDS. No âmbito deste esforço a camisinha ganhou nomes; tentou-se popularizá-la aproximando-a do cotidiano do cidadão comum. Ela passou a ser sugerida como peça obrigatória do vestuário masculino $e$ feminino e sinal de uma nova etiqueta sexual. Não carregar sempre um preservativo de borracha passou a ser deselegante. Além disso, a pedagogia, muito ambiciosamente, esforçava-se em produzir uma redescrição $e$ ressignificação dos atos sexuais de homens e mulheres. Em tal tentativa, buscava-se estimular a substituição de antigas práticas sexuais por outras novas ou a agregação de diferentes itens ao menu sexual. Intimidade ali ganhou novos sentidos, deslocando-se a centralidade do sexo penianovaginal ou anal e enfatizando-se o valor erótico do olhar, dos toques, das carícias e, no limite, do abraço fraterno. Vistas como formas de sexo mais que seguro, essas práticas foram postas no mesmo patamar erótico das suas predecessoras arriscadas.

Esta abordagem tomava como certa a possibilidade de, por meio do ensino, vencer a epidemia pela conversão de sexo comum agora tornado perigoso em sexo seguro, tornado, por sua vez, sexo sanitário e oficial. Mais profundamente, assumia que se trabalhava com uma população cujos déficits emocionais a afastava de um tipo e volume de comunicação que levasse ao diálogo entre parceiros necessário à plena implantação do novo regime sexual. Por meio de palestras e workshops, supunha-se que tais déficits poderiam ser superados. Essas suposições organizaram-se em torno do princípio analítico que modelou muito da pedagogia anti-AIDS crítica durante toda essa fase e que se projetou nos anos seguintes: a certeza de que o comportamento de saúde inadequado residia na ignorância individual expressa no comportamento sexual inseguro, cuja superação dependia da maior expansão da informação até então negada ou mal-distribuída pelo governo. Uma vez possuída, a informação levaria ao desejo e à efetivação da mudança comportamental.

Centrada na idéia de responsabilidade individual, a estratégia campanhista-informacionista manteve-se fiel à tradição punitiva que com freqüência a acompanha. No Brasil, o rigor da nova etiqueta sexual levou ao silêncio (e à mentira) dezenas, centenas e milhares de indivíduos que vez por outra (ou freqüentemente) saíam do figurino. A interdição da possibilidade de afirmar a incapacidade de aderir plenamente a tal etiqueta e de, a partir disso, buscar outras formas de proteção; a repressão de desejos; a expansão de tensões emocionais; a sensação de incapacidade individual e os sentimentos de culpa por uma eventual infecção foram, certamente, os produtos principais, mas não os únicos, derivados do traço coercitivo dessa estratégia.

A ação saneadora do tempo, com diferentes graus de sucesso, mostrou a necessidade de mudanças e de reconhecimento dos limites dos métodos de intervenção prevalecentes. Apesar do extremo esforço posto por diversos setores envolvidos na luta anti-AIDS pela preservação da pedagogia em questão, a percepção crescente na falibilidade do condom não a deixou completamente ilesa. Aqui, e mundo a fora, o discurso do sexo seguro (safe sex) teve de acrescentar mais uma palavra (e a depender da língua, uma 
letra) ao seu vocabulário. Em tempos de AIDS, o sexo correto foi muitas vezes denominado de seguro (safe), mas em muitas outras, pelas entidades e pessoas envolvidas, foi também chamado de mais seguro (safer sex). Em outros termos, significou que a idéia de tornar o uso da camisinha uma norma cultural à qual todos adeririam sempre e indefinidamente era uma proposta que precisava ser re-estruturada, admitindo-se que mesmo seu uso contínuo não conferia total segurança contra a infecção. Significou também que se fazia necessário repensar as estratégias de intervenção vigentes. Novas propostas e perspectivas pediam passagem.

A fase focalista $e$ a busca das especificidades grupais A chegada dos anos de 1990 jogou novas luzes nas idéias sobre educação contra a AIDS e sugeriu diferentes pautas interventivas. A perspectiva campanhista e seus pressupostos continuaram firmes, mas dividindo a posição de estratégia privilegiada com a intervenção mais dirigida a grupos específicos que até então era residual ou secundária. Isso foi conseqüência também, em grande parte, das mudanças nos modos de financiamento da ação anti-AIDS no mundo, em especial a exigência das charities do hemisfério norte - fontes essenciais de apoio às nossas ONGs - de que as solicitações de recursos fossem feitas a partir de definições bem claras no que dizem respeito às populações-alvo, aos métodos de ação $e$ às possibilidades de avaliação de resultados (Durão, 1995). Desta forma, a partir de 1990, a perspectiva de intervenção mediante projetos bem demarcados de atuação com uma clientela específica passou a definir o modus operandi da pedagogia crítica anti-AIDS. A informação continuou sendo um elemento imprescindível; mas não era mais equalizada ao todo do trabalho educativo/preventivo, além do que ganhou uma maior sofisticação intelectual. Ativistas afirmavam, por exemplo, que

\footnotetext{
'Prevenção' já não é um conceito genérico e abstrato (...) nem se resume a difundir informação pré-fabricada: há que fazer chegar esta informação às diversas populações sob formas interativas $e$ motivantes. Programas específicos destinados a jovens, crianças, adultos, mulheres, homens, homossexuais, bissexuais, heterossexuais, profissionais da saúde, profissionais do sexo, donas de casa, motoristas de caminhão, usuários de drogas, e muitas outras categorias apresentadas. A informação não é homogênea nem existem receitas: a melhor receita é criar cada programa com a participação da população, respeitando, porém, o princípio da informação clara e frontal. (Bastos, 1993, p.2)
}

Nesse período, sexo e sexualidade eram vistos menos como atos unitários nos quais pudessem ser facilmente inseridos uma técnica erótica - o sexo mais seguro - e um instrumento de prevenção - a camisinha.

Inversamente, ambos passaram a ser teorizados a partir de uma pluralidade de olhares que, além de visualizar as questões políticas mais amplas ali presentes, dedicavam-se também à apreciação da dinâmica dos micro poderes contidos nas relações afetivas e seu papel na estruturação de 
GÓIS, J. B. H.

comportamentos de risco. Em função disso, os temas da negociação, das relações de gênero, da auto-estima e das emoções em geral ganharam maior relevância $e$ as intervenções passaram a incidir mais na modificação dos cenários sócio-culturais onde os atos sexuais se dão. Isto só foi possível, graças à reorganização do quadro analítico mais amplo por onde se moviam os raciocínios sobre o processo de educação e saúde no campo da AIDS.

O paradigma da vulnerabilidade social

Tal reorganização se deu no corpo de um esforço internacional de compreender a contínua expansão da epidemia em áreas e grupos humanos até então pouco atingidos e de avaliar os impactos reais das atividades antiAIDS desenvolvidas até então. Uma das principais conclusões desse esforço foi o amplo reconhecimento dos limites e mesmo do fracasso das políticas de disseminação em massa de informação e do simplismo das idéias educacionais nelas contidas. Tal esforço identificou também que estratégias mais elaboradas tiveram maior sucesso, sem no entanto atingir um grau satisfatório de eficácia e eficiência. Sobre isso, afirmava-se que modelos de luta anti-AIDS fundados na tríade informação e educação, prestação satisfatória de serviços de saúde e sociais e construção de um ambiente não discriminatório e acolhedor para os doentes atingiram muitos dos seus objetivos, mas não permaneceram imunes a limitações críticas. Dizia-se que, se de um lado tais modelos levaram à consolidação de programas interventivos mais abrangentes e avançaram na formatação de um padrão assistencial que criou condições materiais mais favoráveis à prevenção primária e secundária pela distribuição ampliada de condons e medicamentos, de outro lado, foram marcados pelo caráter local, pela ausência de análises críticas amplamente discutidas, incapacidade da resposta em face ao crescimento do problema, burocratização e isolamento.

A partir daí as ONGs brasileiras passaram a apontar para a inadiável necessidade de se buscar novos patamares de análise e intervenção junto à epidemia de AIDS. Sugeriam, especificamente, a importância de se entender $e$ intervir nos processos sociais que respondiam mais diretamente pela incapacidade de indivíduos e determinados grupos sociais evitarem a exposição ao HIV. Foi a partir dessas balizas que se consolidou no Brasil o conceito de vulnerabilidade social, entendido como a relação entre pertencimento a grupos marginalizados e comportamentos de risco (Mann et al., 1993; Ayres, 1999; Paiva, 2000; 2002). Submetidos às formas mais diversas de discriminação, a tais grupos eram negadas informações $e$ educação compatíveis com suas necessidades, acesso pleno aos serviços de saúde e possibilidades de crescimento dentro de ambientes onde fosse possível desenvolver uma saudável identidade individual e grupal (Abia, 1993). Esse raciocínio mais geral iria ser repetido em relação a grupos sóciosexuais específicos os mais diferentes. Sobre os homossexuais, por exemplo, dizia-se:

a prática continuada de comportamentos de risco entre esta população está intimamente associada ao isolamento social e a conflitos psicológicos provocados pela discriminação e por preconceitos amplamente disseminados pela sociedade. (Abia, 1996, s/p)

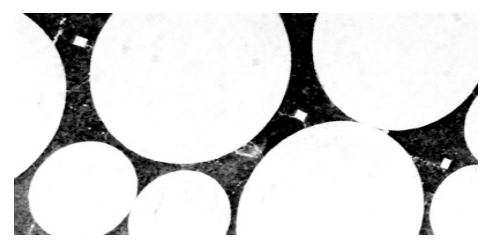




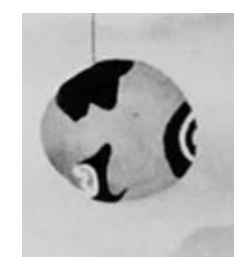

Mas o ponto de partida principal não era a sexualidade. Não que ela não fosse considerada um fator crucial a partir do qual foram modelados programas específicos. Todavia, foram a divisão entre classes sociais e a questão da pobreza que assumiram a função de agente modelador da versão brasileira do novo paradigma.

Os ambientes, grupos sociais e pressupostos do novo paradigma: rupturas e continuidades

Ao colocar os dilemas da pobreza como marco divisor essencial do novo estágio do debate, erigiu-se uma nova unidade de intervenção: a comunidade. Tal fato acompanhou movimentos mais amplos de revalorização das instâncias locais já então presentes no debate sobre a gestão da saúde e novas formas de convivência influenciados, em boa medida, pela contribuição habermasiana. Apesar de seu desenvolvimento dentro de um lastro crítico, é possível supor que os caminhos da incorporação do conceito de comunidade no movimento anti-AIDS brasileiro não se deu com o volume necessário de críticas a sua estrutura interna, história e a suas implicações operacionais. Obviamente, não se trabalhou em torno de uma visão totalmente ingênua que equalizava comunidade, união e partilhamento de objetivos e princípios; mas, ao mesmo tempo, não se deixou de incorporar muito das versões mais positivistas daquele conceito. Isto teve implicações relevantes no que toca aos procedimentos de abordagem educacional, algo que se agravou muito em função do tipo de apropriação daquele que historicamente tem sido o principal construto auxiliar do conceito de comunidade - participação social. Foi no uso dele que se revelaram muitas das dificuldades das nossas ONGs/AIDS de reproduzir o seu discurso mais progressista quando atuavam em contextos e em atividades mais específicas.

Em alguns projetos a participação parecia corresponder à idéia de adesão a pautas interventivas estabelecidas pelas organizações executoras da ação. Isto talvez tenha decorrido de uma percepção dos pobres como aglomerados populacionais "que se apresentam enquanto foco de fácil penetração e disseminação da epidemia" (Gonçalves \& Santana, 1994, p.43). Mas, é também muito provável que noções de povo e pobreza oriundas das vulgatas marxistas nas quais alguns dos principais idealizadores do discurso educacional em tela foram formados tenham contribuído para tanto. Sob tais noções, as massas pobres eram infantilizadas e vistas como inexperientes e portadoras de uma consciência mágica, o que sugeria a necessidade de que lideranças esclarecidas as conduzissem a um novo patamar de compreensão e ação.

Seja lá como for, sob a rubrica comunitária desenvolveram-se, tanto pela prestação direta de serviços quanto pela formação de agentes comunitários multiplicadores do saber, diversas atividades que buscaram melhorar o nível de conhecimento e de manuseio dos riscos de infecção de uma população efetivamente necessitada. Favelas e morros tornaram-se alvos preferenciais de algumas propostas. Em intervenções desse tipo reconhecia-se que a mensagem educacional teria que ser diferenciada em função das peculiaridades de cada gênero, estrato social e etnia, o que levou diferentes ONGs, com populações distintas, a desenvolver materiais específicos para as 
suas clientelas e a salientar a necessidade de uso de um vocabulário adequado à linguagem local. Ao lado disso, apontava-se para a importância do aproveitamento dos recursos humanos comunitários, uma vez suposta como certa a maior possibilidade de identificação dos moradores com os agentes educacionais e de saúde oriundos do local.

Esse tipo de trabalho organizava-se em torno de uma série de pressupostos. Um deles é o que dizia que uma vez atingido um certo volume de massa crítica nas comunidades, as mudanças comportamentais mais gerais poderiam seguir um fluxo normal de reprodução - seja pela repetição, seja pela pressão daqueles já educados sobre os não-aderentes - rumo à criação de normas de conduta sexual amplamente aceitas. Essencialmente, esperava-se que uma vanguarda esclarecida impulsionasse a mudança necessária. Daí porque tais projetos eram com freqüência de curta ou média duração. Assim, revelando a sobrevivência de traços da fase campanhista em seu interior, esses projetos guardavam consigo a crença de que a transposição de informações feita com adequações e de forma culturalmente sensível pudesse dar conta de um tipo de dinâmica que exigia um raciocínio mais complexo.

Além dos trabalhos no plano comunitário, as ONGs ingressaram de forma maciça em uma série de ambientes. É como se descobrissem as múltiplas diversidades concretas encobertas pela visão do social indiferenciado que marcou o discurso delas nos anos 19805. Um dos ambientes preferenciais foram os denominados locais de trabalho (Vianna E Vieira, 1994; Duarte, 1994). Neles, as ONGs(AIDS tanto criaram quanto atenderam a uma demanda por serviços. Não que elas já não tivessem em alguma medida feito incursões nesse domínio. Mas, o caráter campanhista referido anteriormente não permitia que sua inserção ali fosse mais do que ocasional.

As escolas também foram alvo de projetos específicos. Os diversos episódios de discriminação contra crianças registrados no sistema escolar brasileiro sugeriram a necessidade de ação. Material educacional foi elaborado visando à ruptura de preconceitos e falsas concepções sobre os mecanismos de transmissão, principalmente a não-transmissibilidade do HIV pelo contato social. Pais e crianças eram alvos preferenciais dessa atividade, enfatizando-se junto a eles a necessidade de solidariedade com os diretamente afetados. Mas educadores e gestores do sistema de educação também receberam especial atenção, tanto por sua capacidade multiplicadora da informação quanto por seu papel na própria disseminação da discriminação (Monteiro \& Branco, 1994).

Populações de rua foram abordadas e mais adiante, na década de 1990, ainda sob os signos do conceito de vulnerabilidade social, mulheres e jovens negros foram tornados alvos preferenciais de intervenção. Essas mesmas populações negras foram atingidas por projetos que tinham como alvos as casas de candomblé e umbanda. Ali foram estabelecidos vínculos cada vez mais sólidos entre as chamadas comunidades de terreiro e as ONGs/AIDS, num movimento que avançou das preocupações mais imediatas sobre a AIDS para um campo mais amplo de indagações sobre desigualdade de participação social demarcada por linhas de adesão a determinadas práticas

\author{
${ }^{5}$ As ONGs/AIDS \\ percorreram um longo \\ caminho até \\ incorporarem a \\ diversidade de \\ identidades sócio- \\ sexuais existente no \\ Brasil. Na base disto \\ esteve o caráter \\ universalista do seu \\ discurso e o \\ conseqüente \\ ocultamento que ele \\ produzia de grupos \\ menos visíveis. Daí \\ porque mulheres \\ heterossexuais, negros, \\ lésbicas, idosos, só \\ gradativamente vão \\ sendo objeto de \\ intervenção e, por \\ conseguinte, passam a \\ ocupar um local \\ específico e a possuir a \\ voz própria que foi \\ retumbantemente \\ instigada pelas ONGs/ \\ AIDS.
}


6 Em realçando o ineditismo dos projetos aí incluídos, não queremos afirmar a inexistência de ações anteriores voltadas para a população homossexual desenvolvidas pela ABIA e outras instituições dentro $e$ fora do Rio de Janeiro.

\footnotetext{
${ }^{7}$ Por concepção

universalista refiro-me à dimensão do discurso crítico anti-AIDS que combatia a associação entre a doença e os grupos minoritários. Ao fazê-lo, tal discurso propunha que todos eram passíveis de contrair o vírus e que pela necessidade de se construir uma pauta de trabalho mais humanitária, era imprescindível que todos se sentissem membros de uma mesma família sorológica.
}

religiosas (ISER,1993). Publicação específica para esse grupo chegou ao mercado e a língua Iorubá foi adicionada ao rol das várias linguagens descritivas da AIDS. Isso não somente porque termos nigerianos passaram a ser utilizados nessa ou naquela publicação, mas porque um tipo de percepção peculiar às tradições afro-brasileiras se erigiu como uma das matrizes explicativas dos sentidos da doença e dos meios de se superá-la.

Os chamados divergentes sexuais passaram a ser cada vez mais objeto de atenção. Servindo-se de atividades iniciadas na década anterior, consolidaram-se trabalhos junto a prostitutas e travestis (Barreto,1994). Umas e outros eram recrutados para atuar como agentes de saúde comunitários. Os profissionais do sexo, de todos os gêneros, foram instruídos para estabelecer medidas de auto-proteção e de proteção para os seus clientes. Mas, a grande novidade, parece-me, foi o trabalho especificamente dirigido a homossexuais, seja pela sua consistência seja pelo atraso no seu início, pois, como é amplamente sabido, foram eles os primeiros e os mais afetados pela epidemia no Brasil 6 .

Uma tendência no discurso das ONGs/AIDS é entender a ausência inicial de trabalhos específicos para os gays como um problema situado fora de seus marcos institucionais. Relatando projeto desenvolvido no Rio e São Paulo, Veriano Terto, da ABIA, afirmava:

No que pese ser plausível, essa explicação pode ser aprofundada ao se the acrescentar mais alguns elementos. O primeiro deles refere-se ao fato de que a concepção universalista da doença ${ }^{7}$ predominante nos anos de 1980, constituía uma barreira à percepção das necessidades particulares desse grupo. Ao mesmo tempo, porque buscava-se dissociar homossexualidade e AIDS, programas específicos foram vistos não somente como ineficazes mas também como indesejáveis do ponto de vista político. Um outro fator repousava na própria concepção de homossexualidade que parece ter impregnado por muito tempo e até hoje as nossas ONGs/AIDS. Embora o paradigma essencialista (Parker \& Gagnon, 1995) tenha sido objeto de profundas críticas por parte de membros das ONGs/AIDS, ele não parece ter sido totalmente superado. Enquanto, de um lado, dizia-se que o comportamento sexual era resultante de forças históricas múltiplas e que detinha significados variáveis, mantinha-se, por outro lado, que a experiência homossexual não constituía um marcador relevante na definição do indivíduo e da sua colocação social.

Seja lá como for, gradativamente a homossexualidade passou a ocupar uma posição central no debate crítico anti-AIDS e, servindo-se da história de identificação com comportamentos homoeróticos de uma grande maioria de membros e dirigentes das principais ONGs/AIDS nacionais, apresentou-se como um dos investimentos de maior consistência com o paradigma da 
GÓIS, J. B. H.

vulnerabilidade social. Emblemático é o projeto Homens Que Fazem Sexo Com Outros Homens, executado pela ABIA e pelos grupos Pela Vidda do Rio de Janeiro e de São Paulo e depois reproduzido em outras cidades do país ${ }^{8}$.

Apoiado em estudos sobre comportamentos de risco que apontavam o isolamento social e os conflitos psicológicos decorrentes da discriminação social entre homossexuais como os seus determinantes, o projeto visava atuar sobre as causas que modelavam tais comportamentos. Em face disso, buscou-se implementar um amplo conjunto de atividades que atingissem as necessidades da população-alvo. Informação e distribuição de condons permaneceram como desencadeadores da intervenção, mas passaram a ser vistos como estágios de menor importância quando comparados a uma abordagem mais sistemática da população-alvo e com as tentativas de conhecimento $e$ intervenção junto à ambiência mais ampla onde ela existia $e$ se movimentava. As ONGs/AIDS foram às ruas e à noite. Homossexuais foram objeto de abordagens corpo-a-corpo e de um novo esquadrinhamento social. Buscou-se conhecer seus locais de encontro, de procura de parceiros sexuais, lazer, paquera e namoro e suas organizações associativas. Esses locais tornaram-se espaços de prevenção: boates e bares possibilitaram a realização de oficinas de sexo seguro em seu interior. Semanalmente foram desenvolvidas atividades de aconselhamento relativas às Doenças Sexualmente Transmissíveis/AIDS - DSTs/AIDS e aos dilemas psicossociais da experiência homoerótica. A presença da população-alvo nas ONGs patrocinadoras do projeto foi estimulada, mas, quando da impossibilidade de fazê-lo, aos interessados eram disponibilizados serviços telefônicos como o Disque-AIDS. Buscou-se a ruptura de uma série de mistificações sobre a homossexualidade produzidas fora e dentro das próprias ONGs/AIDS. Sublinhou-se a imprecisão dos indicadores que sugeriam ser os homossexuais o grupo mais informado. Esta percepção, dizia-se, contribuía para o deslocamento dos esforços para outros grupos vistos como mais vulneráveis. O próprio conceito de homossexualidade foi criticado, tanto por suas raízes médicas e medicalizantes, quanto por sua imprecisão ao agrupar homens que guardam entre si laços identitários os mais diversificados. Assim, afirmava-se que o termo homossexualidade sugeria uma equalização entre identidade sexual e comportamento. Já a nomenclatura Homens Que Fazem Sexo Com Homens era vista como portadora de uma maior capacidade de apreender a multiplicidade (Costa, 1994; Mott, 2002). Buscava-se, com isso, romper com a idéia de que práticas homossexuais são sempre semelhantes, organizadamente definidas segundo um menu de opções permanentes e percebidas igualmente pelas pessoas que as praticam (Parker \& Terto Jr., 1998).

\section{Novas técnicas de intervenção}

Ao lado das novas ambiências e grupos, emergiram também novas técnicas de intervenção. Nelas, sem abrir mão de conceitos políticos os mais importantes, a idéia de indivíduo-cidadão cedeu espaço para a idéia de indivíduo-pessoa. Buscou-se, então, fazê-lo falar, não só dos seus direitos mas também da sua intimidade, das suas vivências, emoções, da sua experimentação como ser no mundo. Não surpreende, assim, que o teatro e
${ }^{8}$ Para conhecimento desse projeto ver Parker \& Terto Jr, 1998.

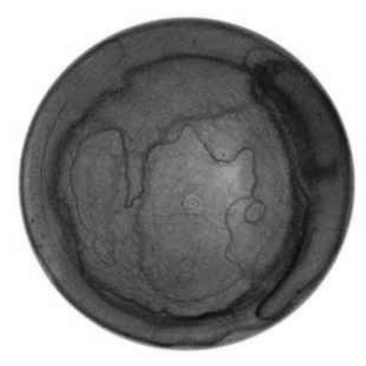


as oficinas de sensibilização tenham sido utilizadas como instrumento técnico privilegiado. Com ambas buscava-se superar a participação reduzida da audiência e, ao dar-lhe voz, reafirmar de modo mais consistente um dos jargões mais repisados pelas ONGs: o de que a AIDS atinge a todos e, portanto, por não ser propriedade de médicos e cientistas, deveria ser expressa, comentada e julgada na primeira pessoa, a do cidadão comum (Prata, 1994; Gapa-SP, 1994).

\section{Rupturas e continuidades: sobrevivências campanhistas na fase focalista}

Esse movimento, que positivamente trouxe o debate sobre a necessidade de utilização de abordagens diferenciadas para os diversos grupos humanos, infelizmente não representou uma ruptura completa com as idéias sobre o processo de ensino-aprendizagem que estiveram subjacentes à estratégia campanhista de educação indiferenciada. Já no final dos anos 1990, o safesex é ainda apresentado como um processo simples e gratificante. Diz um folheto informativo que "sexo seguro é tudo isso. Você transando com alegria, prazer e tranqüilidade, usando a camisinha nas transas com penetração ou descobrindo o sexo sem penetração. Para tudo rolar numa boa, sem grilos" (Abia, 1997b, s/p).

A grande viragem metodológica, assim, conservou pressupostos intelectuais antigos sobre os processos de aprendizagem que geraram em seu interior muito dos mesmos problemas da perspectiva anterior. Além disso, foram fortemente criticadas as pessoas que não utilizavam o condom em todas as suas relações sexuais. Foi como se a especialização do trabalho interventivo servisse como justificador de uma cobrança mais dura à população por parte das ONGs quanto à adesão consistente aos seus ensinamentos.

Nos anos 1990, incorporando mais sofisticadamente conceitos científicos a suas práticas e análises, a pedagogia crítica anti-AIDS defrontou-se, normalmente sem notar, com um dos seus dilemas centrais: ensinar uma etiqueta tão rígida implica sempre premiar os bons alunos e punir, de uma forma ou de outra, os que a ela não conseguem aderir. No centro estava a certeza, mais uma vez, de que a pedagogia em si permanecia correta e que as falhas preventivas situavam-se nos indivíduos. Isto fica visível na avaliação de um projeto dirigido a mulheres negras na qual se vê, por contraste, a atribuição de valores negativos às supostas recalcitrantes. Dizia-se, por

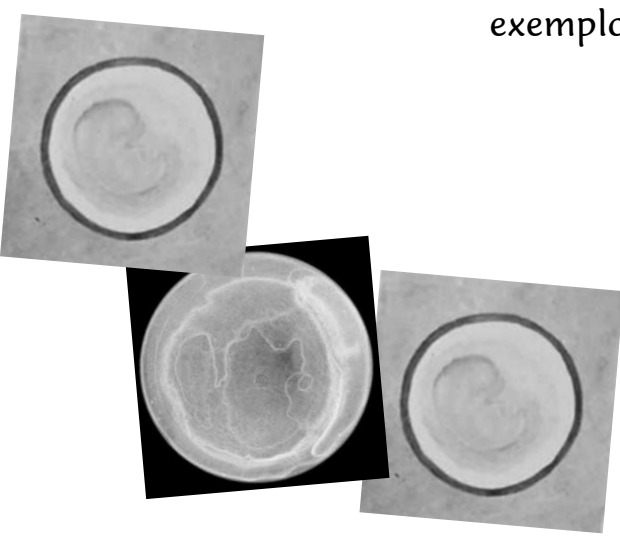

Algumas mulheres quando impedidas pelos parceiros de usar a camisinha na hora que rola aquele tesão, têm dito não, demonstrando amadurecimento, auto-estima e principalmente instinto de preservação. Mas ainda assim a AIDS continua crescendo entre as mulheres, porque muitas não conseguem perceber a singularidade desse momento. Preocupadas em satisfazer o parceiro, acabam tendo procedimentos que as colocam em situação de risco. Em outros momentos, as mulheres não querem perder a transa e acabam fazendo sexo sem os 
GÓIS, J. B. H.

cuidados necessários, o que pode acarretar problemas no futuro.

(Abia, 1997c, p.3)

Pode-se, assim, concluir que o desenvolvimento de projetos educacionais específicos, com suas qualidades e problemas, não eliminou de todo a estratégia campanhista, da mesma forma que esta estratégia nunca impediu que ações educativas especificamente dirigidas para grupos identitários fossem, mesmo pontualmente, levadas a cabo. Além disso, a perspectiva de atuação por grupos não apagou a convicção de que mediante informação correta insistentemente repetida a AIDS seria derrotada ${ }^{9}$.Por fim, vale ressaltar que a infecção individual continuou sendo lida como expressão direta da inércia estatal. Desta forma, a noção de indivíduo assumida, em várias situações, retirava do sujeito infectado a condição de agente da ação $e$ reduzia-o a uma determinação e vítima político-econômica.

Esse tipo de postura - a dissolução do individual dentro da esfera da política e da economia - não seria muito surpreendente se no centro da pedagogia e dos projetos educacionais em causa não estivesse bem situada uma outra noção - a razão - relativamente incompatível com o grau e tipologia da dissolução apontada acima ${ }^{10}$. Tal noção, na sua associação direta com a idéia de escolha racional, foi outro elemento modelador da educação anti-AIDS no Brasil no período em análise. Foi também, como tento mostrar na seção seguinte, um dos seus componentes mais problemáticos.

\section{A razão como problema}

A idéia de razão, na forma como nós a usamos hoje, é basicamente composta das certezas de que nós podemos controlar o ambiente e que as nossas conquistas são conseqüencias das nossas opções e intenções. Outrossim, tal idéia enfatiza a superioridade da racionalidade sobre as outras habilidades humanas e indica o método das ciências naturais como o paradigma mais eficiente para a produção do conhecimento, predição, o alcance da verdade $e$ controle dos fenômenos que nos circundam. Ainda que apresente variações no seu conjunto, esse ideário pode ser visto como um produto da tradição iluminista e como um amplo projeto epistemológico. O racionalismo, contudo, tem sido muito mais do que um programa acadêmico. Com efeito, ele impregnou e, em alguma medida, dependeu da existência de amplos segmentos populacionais das sociedades ocidentais que aderiram a seus pressupostos, o que levou a padrões de comportamento econômico, social $e$ religioso, público e privado, que se davam fora do círculo de debate intelectual. Neste sentido, tal ideário, mais do que uma escola de pensamento, foi um estilo de vida que, fundando-se nos séculos XVII $e$ seguintes, segue-nos até hoje (Gelner, 1994).

No campo da educação para AIDS, as noções de razão e escolha racional foram responsáveis pela derrubada de muitas concepções errôneas e preconceitos sobre o HIV e sobre as pessoas por ele afetadas. Certamente tais noções ajudaram a eliminar uma série de falsas idéias sobre os mecanismos de transmissão deste vírus e, conseqüentemente, reduziram o isolamento das pessoas vivendo com AIDS. Assim fazendo, encorajaram sentimentos de solidariedade em relação aos doentes e produziram uma

\author{
${ }^{9}$ Este tipo de discurso \\ descolou-se de forma \\ muito clara das \\ experiências históricas \\ de educação para a \\ saúde mundial posto \\ que inexistiam bases \\ históricas que \\ pudessem (ou possam) \\ dar suporte à \\ pretensão de que a \\ eliminação de uma \\ epidemia ocorrerá \\ apenas mediante \\ atividades educacionais \\ - mesmo que bem \\ realizadas - e sem o \\ concurso de vacinas ou \\ terapias \\ medicamentosas \\ realmente eficazes. \\ ${ }^{10}$ Produzo uma \\ avaliação das questões \\ teóricas e das \\ implicações práticas \\ dessa contradição em \\ Góis, 200ob.
}


${ }^{11} \mathrm{~A}$ certeza de que a razãoé a condutora máxima do comportamento humano tem sido criticada por diversos pensadores. Freud, por exemplo, afirma que o plano inconsciente, além de conter a nossa história de traumas, fantasias, perversões, desejos não-

civilizados, é aquele que joga o papel central no nosso processo de tomada de decisões. Embora essa linha de reflexão venha sendo extremamente útil na área clínica e na análise social, no campo da educação e AIDS parece ter encontrado um solo pouco fértil para sua expansão, tendo pouca influência sobre ele.

12 Junto a isto existe ainda a dificuldade real de obtenção e/ou manutenção da ereção quando do uso de condons durante o intercurso sexual um obstáculo de difícil superação para muitos homens. $\mathrm{O}$ posicionamento das ONGs em relação às dificuldades de incorporação plena do condom no cotidiano sexual dos brasileiros certamente sofreu revisões ao longo dos anos, as quais traduziram-se no esforço de criar técnicas para erotizar os preservativos de borracha. Isto contudo, não impediu que se mantivesse a conhecida afirmação de que transar de camisinha era o mesmo que chupar bala com papel no domínio das interpretações irracionais e popularescas. melhoria na qualidade de suas vidas. Contudo, o emprego persistente de tais noções, embora essencial, não se deu de modo a permitir avaliações que auferissem a sua viabilidade, aplicabilidade e eficiência no campo da educação contra a AIDS. Ao contrário, da forma como foram ali empregadas, eram refratárias a exercícios mais ou menos rigorosos e contínuos de (re)exame. Assim, ao tomarem tais noções como veio analítico, político e, principalmente, técnico interventivo privilegiado, as ONGs/AIDS deixaram de lado as controvérsias peculiares a suas histórias $e$, conseqüentemente, deixaram de beneficiar-se dos desenvolvimentos, nem tão recentes, contidos na reflexão sobre elas ${ }^{11}$. Pelo menos duas conseqüencias relevantes derivaram disso. A primeira, vale reafirmar, foi a repetição tautológica da concepção de que a mudança de comportamento sexual era o resultado de decisões conscientes entendidas como produtos do intelecto, subestimando, por exemplo, o papel do inconsciente na modelação do comportamento sexual. A segunda foi a não consideração dos múltiplos significados do sexo não-seguro para pessoas e grupos. Deixou-se de ver que muitas atividades consideradas inseguras podem ser emocionalmente importantes para aqueles que as praticam. Por exemplo: as práticas penetrativas não-protegidas podiam tanto representar mais prazer quanto funcionar como um indicador de maior confiança $e$ intimidade, mútuo-pertencimento e complementariedade entre parceiros sexuais. Conectada a isso estava a questão dos significados e dos efeitos dos preservativos de borracha nas performances sexuais. Como pode ser visto em dezenas de peças de material educativo, tomava-se por certo que o uso de condons poderia ser facilmente assimilado e tornado parte integrante dos jogos sexuais. Não havia nessa esfera, ao contrário, nenhuma certeza: para homens e mulheres, de todos os gêneros, o preservativo de borracha poderia funcionar como um agente impeditivo do prazer e ser visto como um elemento estranho ao setting sexual ${ }^{12}$. Outrossim, se a presença permanente do condom nas interações sexuais reafirmava a possibilidade de segurança e prazer sem doenças, por outro lado nos lembrávamos, a cada interação sexual, que a precaução era ( $e$ é) uma necessidade porque existia um perigo potencial e real presente no sangue, esperma e secreções de todos com o qual teríamos que conviver por muito tempo. Walt Odets sumariou com primor as implicações daí decorrentes. Referindo-se ao preservativo de borracha, afirma

\footnotetext{
Este objeto outrora não-mencionável é agora visto em T-shirts, brincos e chaveiros. Mas no quarto de dormir, o condom tem outros significados. Ele introduz associações freqüentemente perturbadoras $e$ inconscientes cada vez que aparece durante o ato sexual: associações de prazer e violência, sexo e punição, intimidade e ferimento, amar e matar - ou ser morto. Terminado o ato sexual, ele jaz cheio de um fluido letal, uma lembrança concreta dos sentimentos misturados sobre homossexualidade, pecado, punição sofrimento e morte. (Odets, 1995, p.133)
} 
GÓIS, J. B. H.

\section{Finalizando}

Sabe-se que o avanço na produção de medicamentos e uma política relativamente estável de ampliação do acesso aos serviços de saúde aumentou o tempo e melhorou significativamente a qualidade de vida das pessoas afetadas pelo HIV/AIDS. Isso não significa, contudo, que tenhamos conseguido impedir o crescimento do número de pessoas que se infectam $e$ adoecem a cada dia. Ao contrário, relatórios de diferentes agências de saúde, nacionais e internacionais, indicam a expansão da epidemia entre nós (WHO, 1998; Ministério da Saúde, 2001). Paralelamente, profissionais envolvidos com a questão e algumas pesquisas internacionais apontam para um crescente relaxamento das medidas de prevenção em alguns grupos sociais. Estes fatos requerem uma postura crítica em relação às estratégias desenvolvidas para o enfrentamento à AIDS.

Reconhece-se a inestimável contribuição dada pelas ONGs na superação dos preconceitos, no auxílio à construção de um ambiente social menos opressor para os doentes e seus familiares e no aumento dos investimentos estatais no setor. Reconhece-se, também, que o que temos de mais avançado no campo da educação anti-AIDS deve-se à capacidade delas de superar carências de recursos, barreiras políticas, conflitos internos e preconceito social. Contudo, esta mesma perspectiva deve ser hábil na produção de uma crítica capaz de identificar pontos de estrangulamento, retrocessos $e$ dificuldades nas práticas desenvolvidas. Desta forma, é preciso produzir uma avaliação continuada dos princípios analíticos dessas posturas e ajudar a reconstituir permanentemente as utopias que elas acalentam em relação às formas de superação dos dilemas que o HIV colocou para a nossa sociedade.

\section{Referências}

ABIA. Pontos para uma campanha de informação. Bol. Inform. ABIA, n.2, s/p, 1988.

ABIA. Por uma nova estratégia de saúde frente a AIDS. Bol. Inform. ABIA Esp., s/p, 1993.

ABIA. A prevenção à AIDS para homens que fazem sexo com outros homens no Rio de Janeiro e São Paulo. Folheto Informativo, s/p, 1996.

ABIA. AIDS. O que podemos fazer. Bol. Inform. ABIA, s/p, 1997a.

ABIA. Editorial. Bol. Inform. ABIA, s/p, 1997b.

ABIA. Quando elas dizem não. Bol. Arayê, n.7, s/p, 1997c.

ALTMAN, D. Poder e comunidade: respostas organizacionais e culturais à AIDS. Rio de Janeiro: Relume-Dumará, 1995.

AYRES, J. R.; FRANÇA JR., I.; CALAZANS, G.; SALETE, F. H. Vulnerabilidade e prevenção em tempos de Aids. In: BARBOSA, R.; PARKER, R. Sexualidades pelo avesso. Rio de Janeiro: Editora 34, 1999. p.49-73.

BARRETO, M. L. Avaliação em programas de intervenção junto a grupos específicos (prostitutas). In: ENCONTRO NACIONAL DE PESSOAS VIVENDO COM HIV/AIDS, 4., 1994. Rio de Janeiro. Anais... Rio de Janeiro,1994. s/p.

BASTOS, C. Tomar o muro de Berlim como exemplo. Bol. Inform. ABIA, n.20, s/p, 1993.

CAMARGO JR., K. R. Políticas públicas e prevenção em HIV/AIDS. In: PARKER, R.; GALVÃO, J.; SECRON BESSA, M. (Orgs.). Saúde, desenvolvimento e política: respostas frente à AIDS no
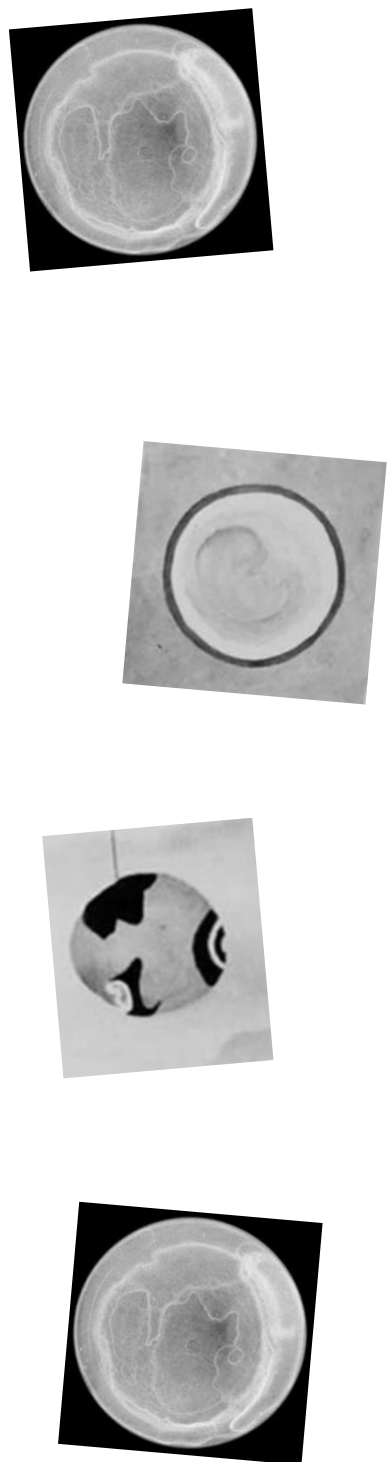


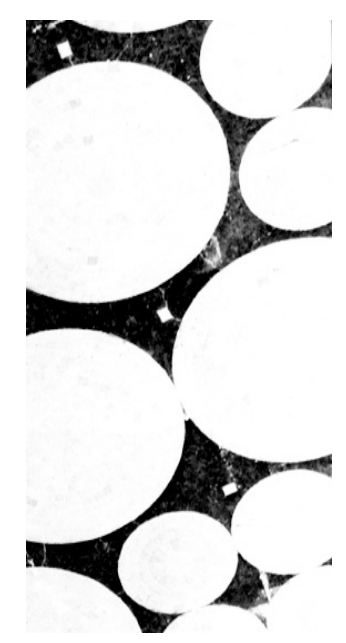

A MUDANÇA NO DISCURSO EDUCACIONAL DAS ONGS/AIDS...

Brasil. São Paulo: Editora 32, 1999. p.227-62.

COSTA, J.F. A inocência e o vício: estudos sobre o homoerotismo. Rio de Janeiro: Relume-Dumará, 1994.

DEAN, L.; MEYER, I. HIV prevalence and sexual behavior in cohort of New York city gay men (aged 18-24). J. Acquire. Immune Defic. Syndr. Human Retrovil., v.8, p.208-11, 1995.

DUARTE, A. AIDS e empresas: formas alternativas em prevenção. In: ENCONTRO NACIONAL DE ONGS/AIDS, 6., 1994. Vitória. Anais... Vitória, 1994. s/p.

DURÃO, J. E. S. Perspectivas de parceria com a cooperação internacional. In: ABONG. As ONGs e a realidade brasileira. São Paulo: ABONG, 1995. s/p.

GAPA-SP. Psicoterapia, arte e lazer. Alternativas para um trabalho com pessoas com HIV/AIDS. In: ENCONTRO NACIONAL DE PESSOAS VIVENDO COM HIV/AIDS. 4., 1994. Rio de Janeiro. Anais... Rio de Janeiro,1994. s/p.

ELIAS, N. O processo civilizador. Rio de Janeiro: Jorge Zahar, 1994.

ERNI, J. Unstable frontiers: technomedicine and the cultural politics of "curing" AIDS. Minneapolis: University of Minnesota Press, 1994.

FAUSTO NETO, A. Comunicação e mídia impressa: estudo sobre a AIDS. São Paulo: Hacker, 1999.

GELNER, E. Reason and culture: the historic role of rationality and rationalism. Oxford: Blackwell, 1994.

GÓIS, J. B. H. A conservadorização do discurso anti-AIDS nos Estados Unidos - anos 90. Serv. Soc. Soc., n.58, p.145-67, 1998.

GÓIS, J. B. H. Vestígios da força das palavras: escritos sobre a AIDS. 1999. Tese (Doutorado). Faculdade de Serviço Social, Pontifícia Universidade Católica de São Paulo, São Paulo.

GÓIS, J. B. H. A construção das ONGs/AIDS brasileiras: história, idéias e auto-representações (19851998). Ser Social, n.7, p.165-204, 2000a.

GÓIS, J. B. H. Olhos e ouvidos públicos para atos (quase) privados: a formação de uma percepção pública da homossexualidade como doença. Physis, v.10, n.2, p.75-99, 2000b.

GONÇALVES, A.; SANTANA, G. Programa AIDS e periferia. In: ENCONTRO NACIONAL DE ONGS/AIDS, 6., 1994, Vitória. Anais... Vitória, 1994. s/p.

ISER. Relatório de atividades. Rio de Janeiro, 1993. (Mimeogr.)

MANN, J.; TARANTOLA, D.; NETTER, T. (Orgs.). Aids no mundo. Rio de Janeiro: Relume Dumará, 1993.

MINISTÉRIO DA SAÚDE. Boletim epidemiológico, ano XIII, n.2, 23a a 26ª semanas epidemiológicas, julho a setembro de 2000. Disponível em: <http:// www.aids.gov.br/udtv/link31.htm>. Acesso em: 12 mai. 2001.

MONTEIRO, S.; BRANCO, C. Trocando o medo pelo saber. In: ENCONTRO NACIONAL DE ONGS/AIDS, 6., 1994. Vitória. Anais... Vitória, 1994. s/p.

MOTT, L. A penetração do preservativo no Brasil do pós-AIDS. Salvador: Bemfam, 1987.

MOTT, L. HSH Um conceito equivocado e homofóbico que perpetua a conspiração do silêncio contra o "amor que não ousava dizer o nome". Disponível em: <http://www.ggb.org.br/ gaysaber.html> Acesso em: 14 ago. 2002.

ODETS, W. In the shadow of the epidemic. Being HIV-negative in the age of AIDS. Durham: Duke 
GÓIS, J. B. H.

University Press, 1995.

PAIVA, V. Fazendo arte com camisinha. São Paulo: Summus Editorial, 2000.

PAIVA, V. Sem mágicas soluções: a prevenção e o cuidado em HIV/AIDS e o processo de emancipação psicossocial. Interface - Comunic., Saúde, Educ.,v. 6, n.11, p.25-38, 2002.

PARKER, R. A construção da solidariedade: AIDS, sexualidade e política no Brasil. Rio de Janeiro: Relume-Dumará, 1994.

PARKER, R.; GAGNON, J. H. Conceiving sexuality: approaches to sex research in a postmodern world. New York: Routledge, 1995.

PARKER, R.; TERTO JR., V. Entre homens: homossexualidade e AIDS no Brasil. Rio de Janeiro: ABIA, 1998.

PIM. Programas Integrados de Marginalidade. Relatório geral de atividades. Rio de Janeiro, 1994. (Mimeogr.)

PRATA, S. Crianças e solidariedade. In: ENCONTRO NACIONAL DE ONGS/AIDS, 6., 1994. Vitória.

Anais...Vitória, 1994. s/p.

TERTO JR, V. Homossexualidades. Um projeto da ABIA para homens que fazem sexo com homens. Bol. Inform. ABIA, n.21, s/p, 1993.

VIANNA, N. S.; VIEIRA, C. Aids no local de trabalho. In: ENCONTRO NACIONAL DE ONGS/AIDS, 6. 1994. Vitória. Anais... Vitória, 1994. s/p.

WHO. Report on the global HIV/AIDS epidemic - june 1998. Disponível em: <http://www.who.int/emchiv/global_report/index.html>. Acesso em: 18 mai. 2001.

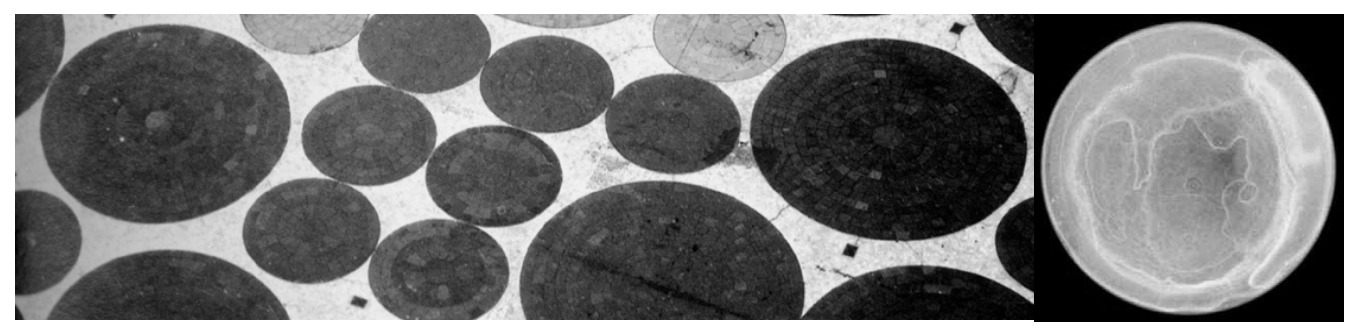

GÓIS, J. B. H. El cambio en el discurso educacional de las ONGs/SIDA en Brasil: historia, concepciones y desdoblamientos prácticos (1985-1998). Interface - Comunic, Saúde, Educ, v.7, n.13, p.27-44, 2003.

Ese artículo examina las principales concepciones contenidas en los discursos educacionales de las ONGs brasileñas de lucha contra el SIDA e intenta analizar como tales discursos incidieron en la elaboración de proyectos de intervención. El artículo indica la existencia de dos fases principales de ese discurso (universalista y focalista), destacando el intercambio de características entre una y otra. Sin negar la relevancia del trabajo hecho, el artículo llega a la conclusión que la adhesión a la critica de la noción de razón llevó a las ONGs/SIDA a la elaboración de modelos analíticos e interventivos simplistas y punitivos.

PALABRAS CLAVE: Educación; Salud; SIDA; ONGs. 